\title{
Germination Patterns in Naturally Chilled and Nonchilled Seeds of Fierce Thornapple (Datura ferox) and Velvetleaf (Abutilon theophrasti)
}

\author{
José Dorado, César Fernández-Quintanilla, and Andrea C. Grundy*
}

\begin{abstract}
Seeds from natural populations of fierce thornapple and velvetleaf collected in a corn-growing area in central Spain were incubated at a range of constant temperatures and water potentials to model the progress of germination on the basis of the accumulation of hydrothermal time. Previous to the germination tests, the seeds were treated in two different ways: (1) dark storage under dry conditions (nonchilled seeds), and (2) burying in the original soil at 10-cm depth during 2 mo in winter (naturally chilled seeds). The results indicated different mechanisms inhibiting germination in both weed species. Whereas fierce thornapple displayed some type of embryo dormancy, the lack of germination in velvetleaf appeared to be entirely due to the seed coat. On the other hand, significant differences between nonchilled and naturally chilled seeds in fierce thornapple were observed, mainly due to the decrease in the mean base water potential of the 50 th percentile in the latter, which indicated a loss of dormancy by exposure of the seeds to natural conditions. Hydrothermal time appears to be a good description of the germination patterns in both weed species, but in the case of fierce thornapple, only for naturally chilled seeds. Thus, the development of the hydrothermal model in fierce thornapple raises some questions for consideration concerning the influence of the type of seeds (conditions of storage, pretreatments of the seeds before germination tests) on its germination capacity.
\end{abstract}

Nomenclature: Fierce thornapple, Datura ferox auct. non L. DATFE; velvetleaf, Abutilon theophrasti Medik. ABUTH; corn, Zea mays L.

Key words: Weed population dynamics, population-based threshold models, dormancy.

Two of the main broadleaf species causing weed problems in corn crops in central Spain are fierce thornapple and velvetleaf. The success of these species is attributable to poor weed control by PRE herbicides as well as their ability to produce a high number of seeds per plant (Ballaré et al. 1987; Zanin and Sattin 1988). The inefficiency of these herbicides on these annual species, in addition to the environmental pressures for reducing the use of residual pesticides, make it necessary to develop nonresidual alternatives for weed control such as the use of POST herbicides or mechanical weeding. The efficacy of these POST treatments is dependent on timing and duration of a flush of weed emergence and the precise moment of these treatments is important to maximize their effect, avoiding the need for subsequent applications (Grundy 2003). Therefore, understanding weed population dynamics and the germination response to environmental conditions is vital to the development of sustainable weed management systems.

Soil moisture and temperature are likely to be the major determinants of seed germination patterns and so these two driving factors can be used as the basis of seed germination models. In this sense, the concept of hydrothermal time (Gummerson 1986) has been initially used to successfully describe the germination time course of crop species (Alvarado and Bradford 2002; Bradford 1990; Dahal and Bradford 1994; Finch-Savage et al. 1998; Rowse and Finch-Savage 2003). Subsequent studies have developed this concept to predict the effects of temperature and water potential on weed seed germination response (Bair et al. 2006; Christensen et al. 1996; Grundy et al. 2000; Roman et al. 1999; Shrestha et al. 1999).

\footnotetext{
DOI: 10.1614 /WS-08-122.1

* First and second authors: Instituto de Ciencias Agrarias, CSIC, Serrano 115 B, 28006 Madrid, Spain; third author: Warwick HRI, Wellesbourne, Warwick CV35 9EF, UK. Current address of third author: National Farmers Union, Agriculture House, Stoneleigh Park, Warwickshire CV8 2TZ, UK. Corresponding author's E-mail: jose.dorado@ccma.csic.es
}

Although the hydrothermal time parameters (hydrothermal time constant, base temperature, mean base water potential and its standard deviation) were considered constant for a seed population, it has been shown that this approach does not describe adequately germination curves produced in the complete range of temperatures and water potentials. In fact, this model can accurately describe seed germination time across the range of suboptimal temperatures, but not precisely at supraoptimal temperatures where an increased value of mean base water potential (i.e., the average water potential threshold below which germination will not occur) with increasing temperatures has been observed (Alvarado and Bradford 2002; Bradford and Somasco 1994). Kebreab and Murdoch (1999) suggested that changes in base water potential of a seed population could be responsible for the delay and inhibition in this range of supraoptimal temperatures. This can be interpreted so that the progressive decrease in mean base water potential may be related to a progressive loss of dormancy in a seed population (Bradford 1995). Therefore, the hydrothermal time concept can also be applied to characterize dormancy loss in seed populations as well as the speed and uniformity of germination in several weed species (Allen and Meyer 2002; Alvarado and Bradford 2005; Bradford 2002; Christensen et al. 1996; Meyer et al. 2000).

Through this study we expected to gain a basic knowledge of the ecological behavior of fierce thornapple and velvetleaf in corn crops of central Spain. The main objective was to develop predictive germination models of these species on the basis of the accumulation of hydrothermal time. The paper reports on experimental tests investigating the germination response over a range of constant temperatures with different water potential levels. Two types of seeds of each species were used in the experiments: (1) seeds stored at constant temperature and humidity, and (2) seeds exposed to the natural environment as a conditioning period to stimulate germination by dormancy loss. Hence, a second objective was to determine the effects of the seed conditioning on the hydrothermal time parameters and, specifically, on the mean 


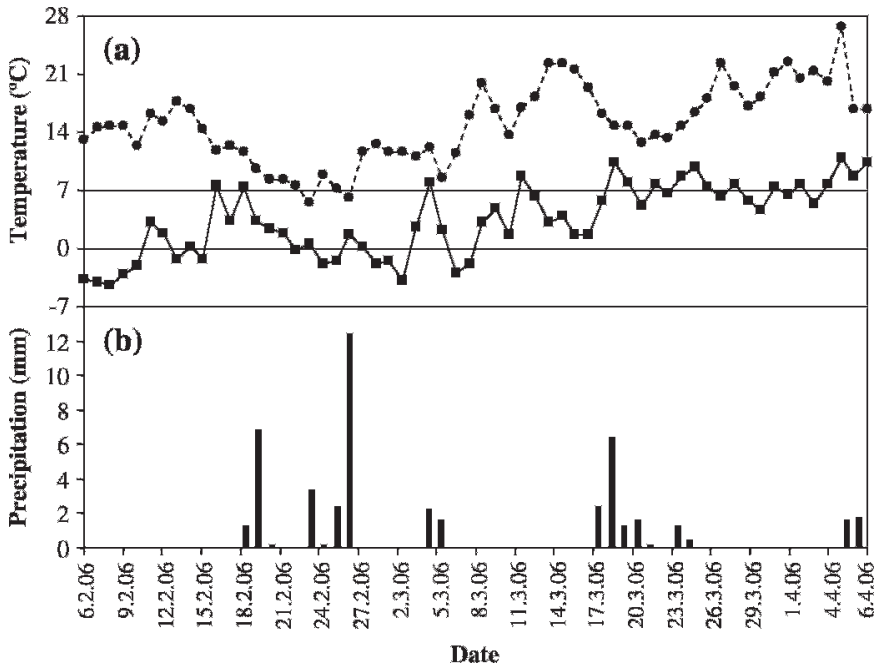

Figure 1. (a) Maximum (dotted line) and minimum (solid line) air temperatures, and (b) daily precipitation (vertical bar) observed at the CSIC experimental farm La Poveda (Madrid, Spain), for the period (February 6, 2006 to April 6, 2006) in which the natural chilling was done.

base water potential distribution as an indicator of the dormancy level.

\section{Materials and Methods}

Seed Material. Mature seeds of fierce thornapple and velvetleaf were harvested in three different years (November of 2004, 2005, and 2006) from natural populations growing on corn fields at the CSIC experimental farm "La Poveda" $\left(40^{\circ} 19^{\prime} \mathrm{N}, 3^{\circ} 29^{\prime} \mathrm{W}\right.$, elevation $\left.535 \mathrm{~m}\right)$ in central Spain. Seeds were air-dried at room temperature for $15 \mathrm{~d}$ to a water content of less than $10 \%$ (dry weight basis). The seeds were stored in sealed plastic jars at 3-5 $\mathrm{C}$ in the dark in dry conditions (hereafter nonchilled seeds) before use. In parallel with the storage, subsamples of seeds from fierce thornapple collected in 2004 and 2005 and from velvetleaf collected in 2005 were pretreated by burying them at a depth of $10 \mathrm{~cm}$ in the original soil, inside plastic bags with a mesh of $1 \mathrm{~mm}$ (hereafter naturally chilled seeds). The natural chilling was carried out during 2 mo, from February 6 to April 6 of 2006 (Figure 1), under spontaneous vegetation established in that site. After exhuming, seeds were stored under dark and dry conditions in sealed plastic jars at 3-5 C until used. This was intended to aid the loss of dormancy (mainly in fierce thornapple seeds) by exposure of the seeds to field conditions. In a previous work (Botto et al. 1998) it was found that burial in a soil with vegetation cover at $10-\mathrm{cm}$ depth during winter season released seeds of fierce thornapple from dormancy.
Germination Experiments. Before using the seeds in the germination experiments, the seeds were subjected to surface disinfection, which consisted of a treatment with $3.2 \%$ fichlor ${ }^{1}$ during $30 \mathrm{~min}$. Preliminary studies showed that this concentration and time were the most effective to disinfect seed coats of both species.

The presence of dormancy in fierce thornapple and velvetleaf seeds was tested in preliminary germination experiments by comparing: (1) control seeds without any treatment; (2) seeds in a mixture of $42 \mu \mathrm{M}$ of fluridone ${ }^{2}$ and $100 \mu \mathrm{M}$ of gibberellin ${ }^{3}$; and (3) pricked seeds, such that part of the seed coat cover was manually removed with a scalpel. The incubation conditions for the preliminary studies were $20 \mathrm{C}$ and $0 \mathrm{MPa}$ of water potential.

Seed germination (i.e., visual appearance of the radicle of at least $1 \mathrm{~mm}$ ) was recorded on four replications of 50 seeds placed on a double layer of filter paper in a 9-cm petri dish in all combinations of six temperatures $(4.9,10.0,15.5,19.7,25.0$, and $30.8 \mathrm{C})$ and six water potential levels $(0,-0.25,-0.5$, $-0.75,-1.0$, and $-1.25 \mathrm{MPa})$. Seeds were pricked before germination tests (preliminary tests had shown that germination significantly increased after pricking; see Table 1). Water potentials were maintained using the appropriate strength solution of polyethylene glycol ${ }^{4}$ (PEG). Each petri dish received $3.5 \mathrm{ml}$ of the appropriate PEG solution, taking precautions to ensure that the ratio of filter paper to PEG solution was sufficient to account for the filter paper exclusion objection made by Hardegree and Emmerich (1990). Individual petri dishes were sealed and placed in resealable polyethylene bags ( 13 by $11.5 \mathrm{~cm}$ ) to avoid evaporation and changes in the water potential of the solutions during the period of the experiment. The temperature of the incubators was monitored every $30 \mathrm{~min}$ by using temperature sensors linked to a data logger. ${ }^{5}$ Seeds were removed as they germinated, at daily intervals initially and less frequently as germination declined. Recording on the lower-temperature treatments was allowed to continue for approximately $3 \mathrm{mo}$, whereas those at higher-temperature treatments were terminated after 3 to 6 wk (until germination stopped completely).

Hydrothermal Time Model and Parameter Estimation. A population-based threshold model approach was considered in the present study to describe seed responses to temperature and water potential. In this approach, it is assumed that, whatever the conditions, seeds will always germinate in the same order, so that each seed can be assigned a value of $G$, which is the specific percentile or fraction of the population at which it germinates (Rowse and Finch-Savage 2003). Although seeds in a population take different times to germinate, the model assumes that they all require the same amount of hydrothermal time. This amount is the hydro-

Table 1. Cumulative fierce thornapple and velvetleaf germination data (\%) observed at $20 \mathrm{C}$ in seeds collected in 2004,2005 , and 2006.

\begin{tabular}{|c|c|c|c|c|c|c|c|c|}
\hline & \multicolumn{5}{|c|}{ Fierce thornapple } & \multicolumn{3}{|c|}{ Velvetleaf } \\
\hline & 2004 & $2004 \mathrm{NC}^{\mathrm{a}}$ & 2005 & $2005 \mathrm{NC}$ & 2006 & 2005 & $2005 \mathrm{NC}$ & 2006 \\
\hline Control & $2 \pm 1.7^{*}$ & $5 \pm 2.6$ & $11 \pm 3.6$ & $6 \pm 6.0$ & $0 \pm 0.0$ & $1 \pm 1.0$ & $2 \pm 1.7$ & $1 \pm 0.9$ \\
\hline Fluridone + GA & $7 \pm 4.2$ & $13 \pm 6.1$ & $41 \pm 14.8$ & N.O. & $4 \pm 3.0$ & $1 \pm 1.0$ & $2 \pm 1.7$ & $3 \pm 1.7$ \\
\hline Pricking & $30 \pm 7.1$ & $53 \pm 5.9$ & $68 \pm 4.7$ & $73 \pm 10.3$ & $14 \pm 11.0$ & $98 \pm 0.9$ & $98 \pm 4.3$ & $99 \pm 1.7$ \\
\hline
\end{tabular}

${ }^{a}$ Abbreviations: NC, natural chilling of seeds during 2 mo (check meteorological conditions in Figure 1); fluridone + GA, mixture of $42 \mu \mathrm{M}$ of $95 \%$ fluridone and $100 \mu \mathrm{M}$ gibberellin; pricking, seeds were pricked manually using a scalpel; N.O., germination was not observed because of the contamination of the dishes.

* Standard deviation on the basis of four replications. 
thermal time constant $\left(\theta_{\mathrm{HT}}\right)$, which is a function of the extent to which the constant water potential $(\Psi)$ and constant suboptimal temperature $(T)$ of the specific seed percentile $(G)$ exceed bases $\left(\Psi_{\mathrm{b}}, T_{\mathrm{b}}\right)$ below which germination tends to zero (Gummerson 1986):

$$
\theta_{\mathrm{HT}}=\left(\psi-\psi_{\mathrm{b}}[G]\right)\left(T-T_{\mathrm{b}}\right) t(G)
$$

where $t(G)$ and $\Psi_{\mathrm{b}}(G)$ are the germination time and base water potential of the specific seed percentile $(G)$. Like the hydrothermal time, the base temperature $\left(T_{\mathrm{b}}\right)$ is assumed constant. Only the base water potential $\left(\Psi_{\mathrm{b}}\right)$ varies with $(G)$ so that the variation in germination time $t(G)$ is entirely caused by the variation in $\Psi_{\mathrm{b}}(G)$. Consequently, knowing the distribution of base water potentials within the population, it is possible to describe seed response of the whole population. Assuming that $\Psi_{\mathrm{b}}(G)$ is normally distributed in the seed population, it can be represented by a mean (e.g., the mean base water potential of the 50th percentile $\left.\Psi_{\mathrm{b}}[50]\right)$ and standard deviation $\left(\sigma_{\Psi_{\mathrm{b}}}\right)$. By incorporating these parameters in Equation 1 (Rowse and Finch-Savage 2003):

$$
\begin{aligned}
\operatorname{Probit}(G)= & \left(\left[\psi-\theta_{\mathrm{HT}} /\left\{T-T_{\mathrm{b}}\right\} t\{G\}\right]\right. \\
& \left.-\psi_{\mathrm{b}}\{G\}\right) / \sigma_{\psi \mathrm{b}}
\end{aligned}
$$

This approach has been shown to adequately describe germination patterns in a wide range of suboptimal constant temperatures (Dahal and Bradford 1994; Roman et al. 1999; Shrestha et al. 1999). Nevertheless, the hydrothermal time model must be able to describe seed germination at both suband supraoptimal temperatures. The optimum temperature is defined as the temperature at which the germination rate $(G R$ $=1 / t[G])$ is maximum. There is a lower temperature $\left(T_{\mathrm{d}}\right)$ that represents the upper limit at which Equation 2 applies. Between $T_{\mathrm{b}}$ and $T_{\mathrm{d}}, G R$ is directly proportional to temperature, but progressive increases in temperature produce smaller and smaller increases in $G R$ until the optimum temperature, where no increase in $G R$ is produced by the increase in temperature. Rowse and Finch-Savage (2003) proposed a method on the basis of empirical data to use Equation 2 above $T_{\mathrm{d}}$. They found that $\Psi_{\mathrm{b}}(50)$ tended to be constant below $T_{\mathrm{d}}$, and increased linearly with temperature at higher temperatures. Assuming that the normal distribution of $\Psi_{\mathrm{b}}(G)$ within the population remains constant (the authors did not find significant differences between the standard deviation of $\Psi_{\mathrm{b}}[G]$ calculated at each temperature), Equation 2 can be extended to describe all temperature ranges using the following equation:

$$
t(G)=\theta_{\mathrm{HT}} /\left(\psi-\psi_{\mathrm{b}}[G, T]\right)\left(T-T_{\mathrm{b}}\right)
$$

in which the effective base water potential for any fraction of the population $(G)$ is defined as:

$$
\begin{gathered}
T_{\mathrm{b}}<T \leq T_{\mathrm{d}}, \psi_{\mathrm{b}}(G, T)=\psi_{\mathrm{b}}(G)_{\mathrm{d}} \\
T>T_{\mathrm{d}}, \psi_{\mathrm{b}}(G, T)=\psi_{\mathrm{b}}(G)_{\mathrm{d}}+m\left(T-T_{\mathrm{d}}\right)
\end{gathered}
$$

where $\Psi_{\mathrm{b}}(G)_{\mathrm{d}}$ is the uncorrected base water potential for that percentile, and $m$ is the slope of the relationship between $\Psi_{\mathrm{b}}(G)$ and temperature at temperatures above $T_{\mathrm{d}}$.

\section{Results and Discussion}

Initial Characterization of Dormancy and Viability. Differences in the germination behavior of fierce thornapple and velvetleaf seeds were observed. Whereas in fierce thornapple some dormancy mechanism seems to be involved, in the case of velvetleaf the lack of germination is apparently due to the seed coat (Table 1). In this sense, the results point to the presence of dormancy in fierce thornapple, because of: (1) a significant effect with fluridone + GA (in seeds collected in 2005, germination reached $41 \%$ after this treatment, compared with $10.5 \%$ in the control) was observed; (2) the cumulative germination of fierce thornapple seeds did not reach $100 \%$ (the maximum germination was $73 \%$ in naturally chilled seeds collected in 2005) at any treatment; and (3) the low percentage of germination in the seeds of fierce thornapple collected in 2006, even after pricking where a maximum percentage germination of $14 \%$ was observed. These results are in agreement with those reported in the literature (Botto et al. 1998), suggesting that, under field conditions, seeds of fierce thornapple are released from dormancy in two steps, the first one during the spring of the first year and the second step during the subsequent winter. The high sensitivity to light perceived by phytochromes has long been known to be involved in dormancy mechanisms of fierce thornapple (de Miguel et al. 2000; Sánchez and de Miguel 1997; Sánchez et al. 1986, 2002), and a minimum period of burial would be needed to reduce or eliminate the light requirement and induce seed germination. On the other hand, the seeds of velvetleaf only germinated in the pricking treatment, even those recently harvested (seeds collected in 2006), indicating that the germination would be prevented by seed coat impermeability. The lack of embryo dormancy in velvetleaf has been known previously. Winter (1960) reported that germination is prevented by the seed coat impermeability and that even immature seeds could germinate after scarification.

Hydrothermal Time Models of Fierce Thornapple. Significant differences between naturally chilled and nonchilled seeds in fierce thornapple were observed. Whereas the percentage of germination in naturally chilled seeds was suitable to construct models, in the case of nonchilled seeds collected in 2004 this percentage was not sufficient to model the germination (Figure 2). In naturally chilled seeds, the percentage of germination in water $(0 \mathrm{MPa})$ was similar at temperatures of 15.5 and $19.7 \mathrm{C}$, and it was reduced as temperature increased above $19.7 \mathrm{C}$ in both years. At 19.7 C, percentage of seeds germinating was progressively reduced by water potentials below $-0.5 \mathrm{MPa}$. Differences caused by water stress in the germination pattern from seeds collected in 2004 and 2005 were mainly observed at temperatures different from 19.7 C. Whereas in seeds collected in 2004 a reduction in the percentage of germination was recorded at water potentials below $-0.25 \mathrm{MPa}$ (no germination occurred below -1.0 MPa), in seeds collected in 2005 germination consistently decreased with increasingly negative water potentials below pure water (no germination occurred below $-0.75 \mathrm{MPa}$ ). In general, maximum final percentage germination was greater in the seeds collected in 2005 than in 2004, both with and without natural chilling. The additional year in the time of storage could have a negative effect on total germination capacity of the seeds collected in 2004 with respect to 2005 .

For hydrothermal time model fitting, a computer program was used to optimize the parameters (Rowse and Finch-Savage 


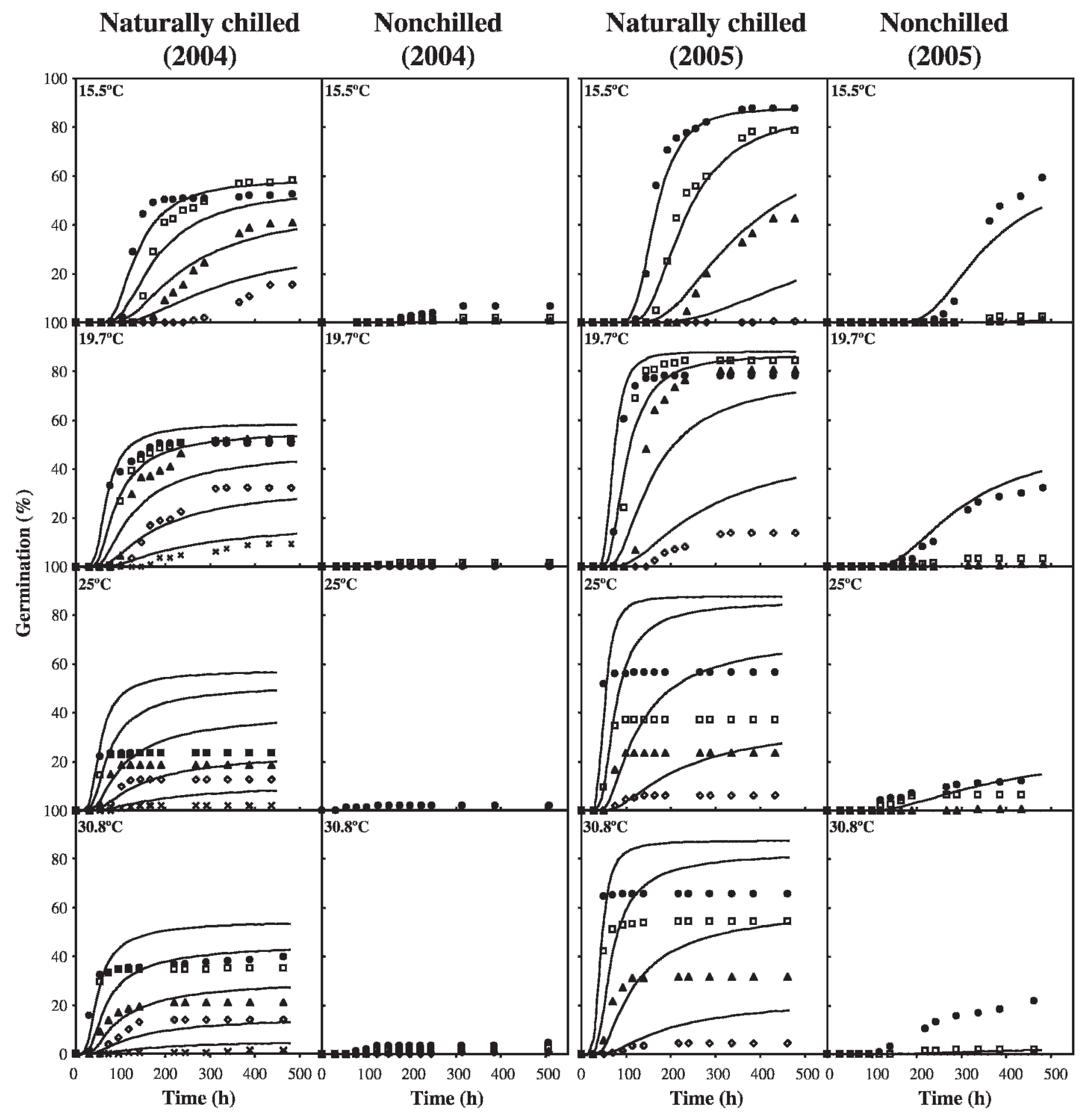

Figure 2. Cumulative germination time courses of naturally chilled and nonchilled seeds of fierce thornapple collected in 2004 and 2005 , and incubated in water potentials of $0(\bullet),-0.25(\square),-0.5(\mathbf{\Lambda}),-0.75(\diamond)$, and $-1.0 \mathrm{MPa}(\times)$ at constant temperatures of $15.5,19.7,25.0$, and $30.8 \mathrm{C}$. The symbols represent the experimental observations and the solid curves are the time courses predicted by the hydrothermal time model using the values shown in Table 2.

2003), so that the residual sum of squares of the difference between observed and predicted germination percentages was minimum (Table 2). The germination response to the full range of temperatures and water potentials was accommodated in the temperature-corrected hydrothermal time model (Equation 3). However, a better description of germination at temperatures of $19.7 \mathrm{C}$ and below was observed, which was progressively worse as temperature increased to $25 \mathrm{C}$ and above (Figure 2). As Rowse and Finch-Savage (2003) reported, the poor fit at higher temperatures occurs because the fitting procedure provides the best fit of the model to the whole population of seeds in an attempt to provide a good description of the full data set.

To assess the possibility of establishing a general model from the hydrothermal models developed using data from different seed populations, a comparison of the $2 \mathrm{yr}$ was performed (Table 2). Although significant differences in the germination response of naturally chilled and nonchilled 


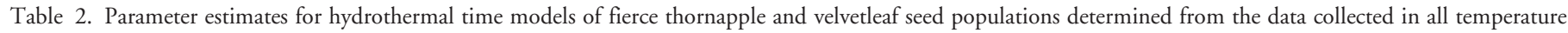
and water potential used in the experiments.

\begin{tabular}{|c|c|c|c|c|c|c|}
\hline & \multicolumn{4}{|c|}{ Fierce thornapple } & \multicolumn{2}{|c|}{ Velvetleaf } \\
\hline & 2004 & $2004 \mathrm{NC}^{\mathrm{a}}$ & 2005 & $2005 \mathrm{NC}$ & 2005 & $2005 \mathrm{NC}$ \\
\hline$\theta_{\mathrm{HT}}(\mathrm{MPa} C \mathrm{~d})$ & $-\mathrm{b}$ & 23.7 & 17.1 & 21.0 & 5.0 & 5.3 \\
\hline$\Psi_{\mathrm{b}}(50)(\mathrm{MPa})$ & - & -0.88 & -0.23 & -0.85 & -0.64 & -0.73 \\
\hline$\sigma_{\Psi \mathrm{b}}(\mathrm{MPa})$ & - & 0.37 & 0.09 & 0.23 & 0.13 & 0.12 \\
\hline$T_{\mathrm{b}}(\mathrm{C})$ & - & 10.4 & 10.0 & 11.4 & 6.8 & 7.2 \\
\hline$T_{\mathrm{d}}(\mathrm{C})$ & - & 18.5 & 15.0 & 18.7 & 15.8 & 15.5 \\
\hline$m(\mathrm{MPa} \mathrm{C}-1)$ & - & 0.032 & 0.023 & 0.020 & 0.010 & 0.005 \\
\hline
\end{tabular}

a Abbreviation: NC, natural chilling of seeds during 2 mo (check meteorological conditions in Figure 1).

${ }^{\mathrm{b}}$ Final percentage germination was not sufficient to fit a hydrothermal time model.

populations were observed, the estimates of hydrothermal parameters $T_{\mathrm{b}}, T_{\mathrm{d}}, \Psi_{\mathrm{b}}(50)$, and $\sigma_{\Psi \mathrm{b}}$ were similar in naturally chilled seeds from the $2 \mathrm{yr}$. Taking into consideration that the treatment of burying the seeds in the soil would be more similar to the natural situation than laboratory storage, the results point to a general and more realistic model when using the data observed in naturally chilled seed populations.

The main differences in the hydrothermal patterns of fierce thornapple were found in $\Psi_{\mathrm{b}}(50)$ values, which were more negative in naturally chilled than nonchilled seeds. In fact, for the seeds collected in $2005, \Psi_{\mathrm{b}}(50)$ was $-0.23 \mathrm{MPa}$ for laboratory-stored seeds and dropped to $-0.85 \mathrm{MPa}$ in naturally chilled seeds. The ecological meaning of a change to more negative values in the $\Psi_{\mathrm{b}}(50)$ distribution would be an increase in the rate of germination for all seeds in the population as well as the stimulation of the germination (dormancy loss) in those seeds with $\Psi_{\mathrm{b}}$ above the environmental water potential (Alvarado and Bradford 2002; Bradford 1996; Ni and Bradford 1993). Several authors have proposed to model dormancy loss on the basis of decreasing $\Psi_{\mathrm{b}}(50)$ so that this single hydrothermal parameter could be used to predict dormancy loss in germination experiments (Allen and Meyer 2002; Alvarado and Bradford 2005; Bauer et al. 1998; Christensen et al. 1996). Seed priming (Bradford and Haigh 1994; Rowse et al. 1999) might also explain the reduction in germination time and the increase in percentage germination occurring in the naturally chilled seeds. This priming effect could be a consequence of alternate wetting and drying, chilling and thermal shock, to which the buried seeds were exposed (Figure 1), and may possibly explain the shift in $\Psi_{\mathrm{b}}(50)$ and, consequently, the increased probability of germination in naturally chilled seeds.

The models gave similar mean base water potential estimation for naturally chilled seeds that had been collected in 2004 and 2005 (Table 2). However, the standard deviation of $\Psi_{\mathrm{b}}$ was notably higher for 2004 seeds than those collected in 2005, indicating a greater spread in time to germination. Debaene-Gill et al. (1994) found that seeds stored after drying at low water potentials could show delayed and asynchronous germination once they are rehydrated.

A further comparison of the hydrothermal time models can be made by applying the factor of normalization $(1-[\Psi /$ $\left.\left.\Psi_{\mathrm{b}}\{G\}\right]\right) t(\mathrm{G})$ proposed by Bradford (1990) to the germination time courses across a range of water potentials. On this timescale, the time courses at different water potentials were normalized to the predicted time courses at $0 \mathrm{MPa}$. Since this approach is not well adapted to supraoptimal temperatures, as a consequence of the increase of $\Psi_{\mathrm{b}}(G)$ related to the increase of $T$ (Alvarado and Bradford 2002), only suboptimal temperature was used to normalize the germination time courses. The results confirmed that both the timing and the extent of germination were significantly different in naturally chilled and in nonchilled seeds (Figure 3a). This figure also illustrated the above-indicated differences in the final extent of germination in the seed collected in 2004 and 2005. In addition, the response of each seed population to the chilling treatments can be illustrated by plotting the normal distribution of $\Psi_{\mathrm{b}}(G)$ using the median or $\Psi_{\mathrm{b}}(50)$ and its standard deviation $\sigma_{\Psi \mathrm{b}}$ (Figure $3 \mathrm{~b}$ ). In naturally chilled seeds, the $\Psi_{\mathrm{b}}(50)$ distribution shifted to more negative values.

The sharp reduction in final germination percentage as well as the timing delay in germination of stored nonchilled seeds compared with the naturally chilled seeds raise several questions. These questions include the influence of the type of seeds, the conditions of storage, and the treatment of the seeds before the germination tests on the embryo and its germination capacity. It is possible that the results of this study would be very different if naturally chilled seeds had not been used. In fact, the apparent break of dormancy associated with the natural chilling of fierce thornapple seeds allowed good and reproducible hydrothermal time models to be obtained. Conversely, the scarce germination observed in nonchilled seed populations (mainly in the first year) did not lend itself to the construction of an accurate hydrothermal model.

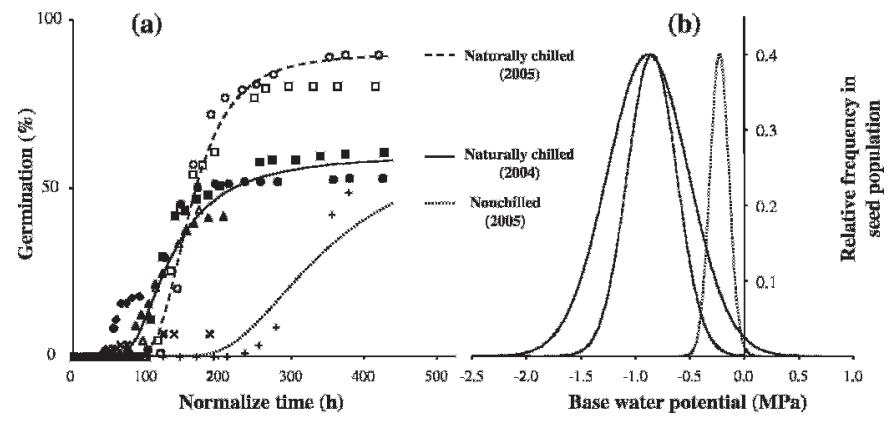

Figure 3. (a) Cumulative germination time courses of naturally chilled seeds collected in 2004 (full symbols) and 2005 (empty symbols) and nonchilled seeds collected in 2005 of fierce thornapple, at the nominal temperature of $15.5 \mathrm{C}$ for a range of water potentials (naturally chilled: 0 [circle], -0.25 [square], -0.5 [triangle], and $-0.75 \mathrm{MPa}$ [rhomb]; nonchilled: $0[\mathrm{X}$ ], and $-0.25 \mathrm{MPa}$ [cross]) plotted on a common normalized timescale according to the factor $(1-[\Psi /$ $\left.\left.\Psi_{\mathrm{b}}\{G\}\right]\right) t(G)$. The curves represent the predicted time courses in the normalized scale on the basis of the parameter shown in Table 2. (b) Normal distributions showing the relative frequencies of $\Psi_{\mathrm{b}}(G)$ values according to the parameter estimates for hydrothermal time models (median $=\Psi_{\mathrm{b}}[50]$; standard deviation $=$ $\sigma_{\Psi \mathrm{b}}$; Table 2). 
Naturally chilled (2005)

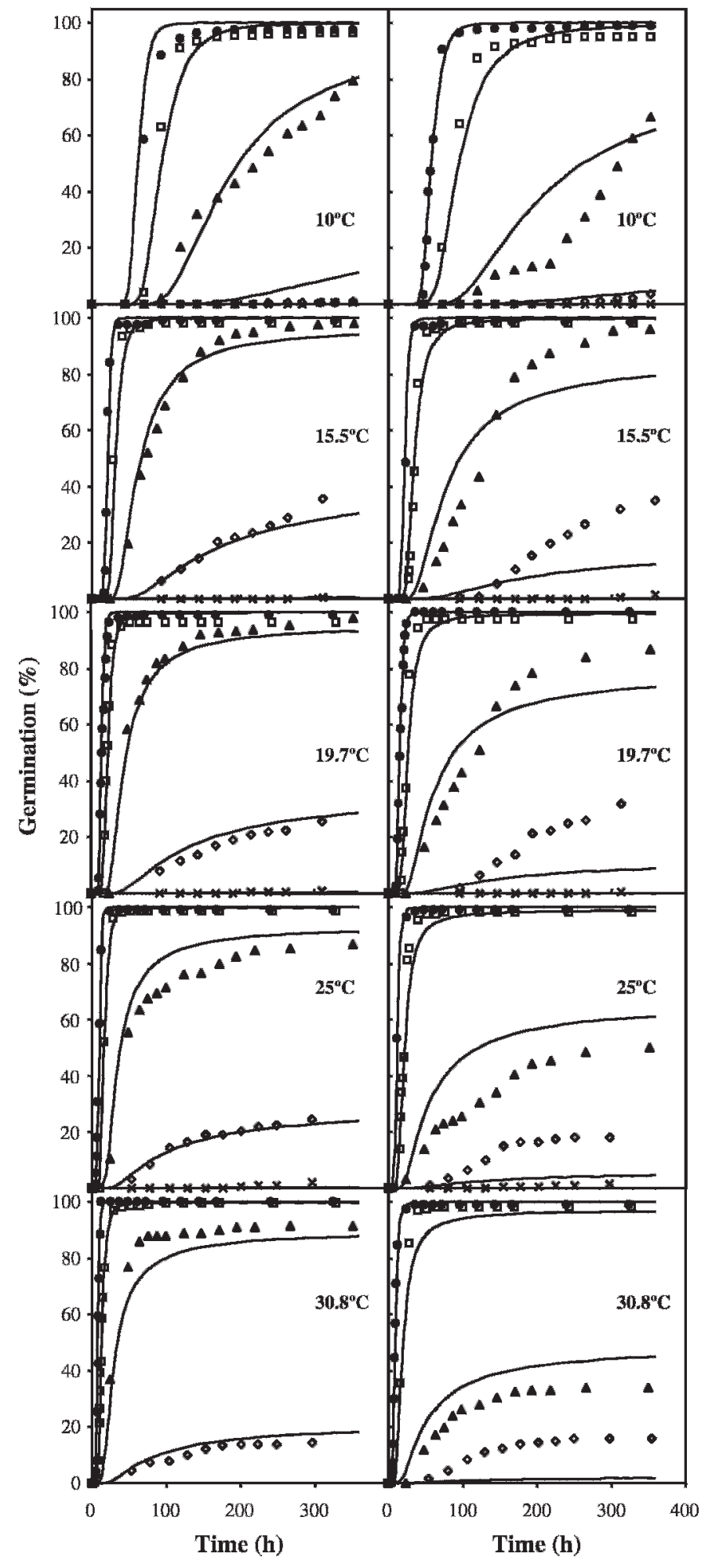

Figure 4. Cumulative germination time courses of naturally chilled and nonchilled velvetleaf seeds collected in 2005 and incubated in water potentials of $0(\bullet),-0.25(\square),-0.5(\mathbf{\Delta}),-0.75(\diamond)$, and $-1.0 \mathrm{MPa}(\times)$ at constant temperatures of $10.0,15.5,19.7,25.0$ and $30.8 \mathrm{C}$. The symbols represent the experimental observations and the solid curves are the time courses predicted by the hydrothermal time model using the values shown in Table 2.
Hydrothermal Time Models of Velvetleaf. Maximum percentage of germination was similar in both the naturally chilled and nonchilled seeds of velvetleaf (Figure 4). The response to temperature observed in pure water and at water potential of $-0.25 \mathrm{MPa}$ was almost constant from $10.0 \mathrm{C}$ to $30.8 \mathrm{C}$. Only at $4.9 \mathrm{C}$ were a delay and a reduction of the germination percentage (approx. 75\% germination after $550 \mathrm{~h}$ of incubation in pure water; data not shown) recorded. The percentage of seeds germinating was progressively reduced by water potentials below $-0.5 \mathrm{MPa}$, mainly at $10.0 \mathrm{C}$ and below. Some differences in the germination pattern from naturally chilled and nonchilled seeds occurred at the lowest water potentials (below $-0.5 \mathrm{MPa}$ ) and at temperatures above 19.7 C and below $15.5 \mathrm{C}$, where the percentage of germination consistently decreased in nonchilled seeds.

In contrast to fierce thornapple, estimates of hydrothermal parameters did not show significant differences between naturally chilled and nonchilled seeds of velvetleaf. Since this approach seems to work in both seed treatments, there is a real possibility of establishing a general model from the hydrothermal parameters estimated with data from different seed populations, but importantly this model would only be valid for velvetleaf seeds that have lost the seed coat impermeability, for example following some natural damage to the seed coat after a period in the soil. The small differences observed in $\Psi_{\mathrm{b}}(50)$, in addition to the high germination percentage in both natural chilling and nonchilling treatments, confirm the absence of embryo dormancy mechanisms in this species (Winter 1960).

Normalization of the time courses at different water potentials in the range of suboptimal temperatures further illustrates the similarity in the germination response between naturally chilled and nonchilled treatments (Figure 5a), with no significant differences in the timing and extent of germination between the seed populations. The lack of variability in the times taken to germination among the seeds was a reflection of the small differences in their $\Psi_{\mathrm{b}}(G)$ distribution (Figure 5b).

In conclusion, different patterns of germination response in fierce thornapple and velvetleaf were found. Whereas some

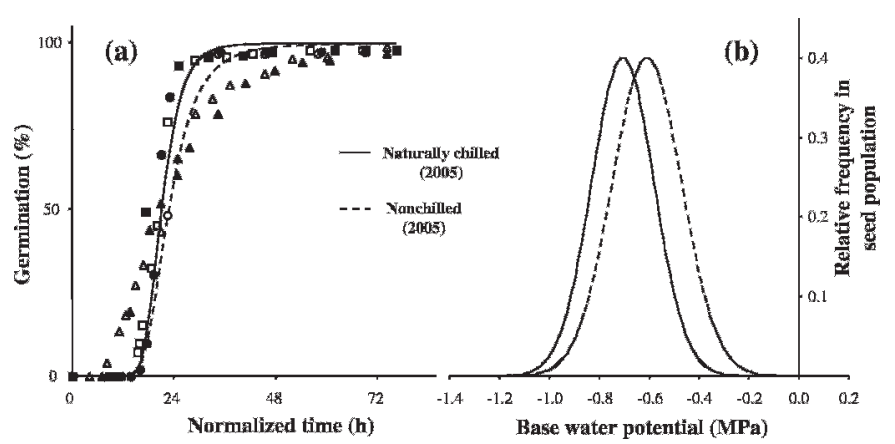

Figure 5. (a) Cumulative germination time courses of naturally chilled (full symbols) and nonchilled (empty symbols) velvetleaf seeds collected in 2005 at the nominal temperature of $15.5 \mathrm{C}$ for a range of water potentials ( 0 [circle], -0.25 [square], and $-0.5 \mathrm{MPa}$ [triangle]) plotted on a common normalized timescale according to the factor $\left(1-\left[\Psi / \Psi_{\mathrm{b}}\{G\}\right]\right) t(G)$. The curves represent the predicted time courses in the normalized scale on the basis of the parameter shown in Table 2. (b) Normal distributions showing the relative frequencies of $\Psi_{\mathrm{b}}(G)$ values according to the parameter estimates for hydrothermal time models $\left(\right.$ median $=\Psi_{\mathrm{b}}[50] ;$ standard deviation $=\sigma_{\Psi_{\mathrm{b}}}$; Table 2$)$. 
type of embryo dormancy seems to be involved in fierce thornapple, the germination of velvetleaf would only be prevented by the impermeability of seed coats. This is in agreement with the broad emergence periodicity generally observed in the field for fierce thornapple and with the short emergence period observed in velvetleaf (generally coinciding with the start of cultivation) in the conditions of central Spain (Dorado et al. 2009). Dormancy is likely to be responsible for the asynchronous establishment of fierce thornapple over a wide range of conditions for different lots within the soil seedbank. In contrast, the germination response of velvetleaf only depends on the proportion of seeds able to germinate in optimal conditions (temperature optimum of $16 \mathrm{C}$ ), which occur during the first corn growth stages, and possibly following some mechanical damage to the seed coats making them permeable during seedbed preparation.

Hydrothermal time provided a good description of the germination time course for both weed species, but, in the case of fierce thornapple, only naturally chilled seeds (those that were pretreated in natural conditions during a 2-mo period) were useful to elaborate an accurate model. The natural chilling treatment seems to provide the most useful data for the development of the hydrothermal time model, and importantly the seeds have been exposed to conditions most similar to those found in a naturally occurring seedbed environment. In contrast, germination tests using fierce thornapple seeds that were stored in constant temperature and humidity levels did not provide such good information since the scarce final percentage germination was not sufficient to develop a precise model.

\section{Sources of Materials}

${ }^{1}$ Dichloroisocyanuric acid sodium salt dihydrate (98\% AT), Sigma-Aldrich Ltd, Gillingham, Dorset, UK.

${ }^{2}$ Fluridone (PESTANAL ${ }^{\circledR}$, analytical standard), Sigma-Aldrich Ltd, Gillingham, Dorset, UK.

${ }^{3}$ Gibberellic acid ( $\geq 90 \%$ gibberellin $A_{3}$ basis), Sigma-Aldrich Ltd, Gillingham, Dorset, UK.

${ }^{4}$ Polyethylene glycol solution (avg. mol. wt. 8,000), SigmaAldrich Ltd, Gillingham, Dorset, UK.

${ }^{5}$ DL2e Data Logger, Delta-T Devices Ltd, Burwell, Cambridge, UK.

\section{Acknowledgments}

This research was funded by the Spanish MEC (program "Salvador de Madariaga", ref. PR2006-0003) and by the Spanish CICyT (project AGL2005-06180-C03-01). The authors thank Dr. H. R. Rowse for advice with development of the hydrothermal time models and Dr. P. Neve for helpful suggestions for the sterilization of the seeds and preparation of the PEG solutions.

\section{Literature Cited}

Allen, P. S. and S. E. Meyer. 2002. Ecology and ecological genetics of seed dormancy in downy brome. Weed Sci. 50:241-247.

Alvarado, V. and K. J. Bradford. 2002. A hydrothermal time model explains the cardinal temperatures for seed germination. Plant Cell Environ. 25:1061-1069.

Alvarado, V. and K. J. Bradford. 2005. Hydrothermal time analysis of seed dormancy in true (botanical) potato seeds. Seed Sci. Res. 15:77-88.
Bair, N. B., S. E. Meyer, and P. S. Allen. 2006. A hydrothermal after-ripening time model for seed dormancy loss in Bromus tectorum L. Seed Sci. Res. $16: 17-28$.

Ballaré, C. L., A. L. Scopel, C. M. Ghersa, and R. A. Sánchez. 1987. The demography of Datura ferox (L.) in soybean crops. Weed Res. 27:91-102.

Bauer, M. C., S. E. Meyer, and P. S. Allen. 1998. A simulation model to predict seed dormancy loss in the field for Bromus tectorum L. J. Exp. Bot. 49:1235-1244.

Botto, J. F., R. A. Sánchez, and J. J. Casal. 1998. Burial conditions affect light responses of Datura ferox seeds. Seed Sci. Res. 8:423-429.

Bradford, K. J. 1990. A water relations analysis of seed-germination rates. Plant Physiol. 94:840-849.

Bradford, K. J. 1995. Water relations in seed germination. Pages 351-396 in J. Kigel and G. Galili, eds. Seed Development and Germination. New York: Marcel Dekker.

Bradford, K. J. 1996. Population-based models describing seed dormancy behaviour: Implications for experimental design and interpretation. Pages 313-339 in G. A. Lang, ed. Plant Dormancy: Physiology, Biochemistry and Molecular Biology. Wallingford, UK: CAB International.

Bradford, K. J. 2002. Applications of hydrothermal time to quantifying and modeling seed germination and dormancy. Weed Sci. 50:248-260.

Bradford, K. J. and A. M. Haigh. 1994. Relationship between accumulated hydrothermal time during seed priming and subsequent seed germination rates. Seed Sci. Res. 4:63-69.

Bradford, K. J. and O. A. Somasco. 1994. Water relations of lettuce seed thermoinhibition. I. Priming and endosperm effects on base water potential. Seed Sci. Res. 4:1-10.

Christensen, M., S. E. Meyer, and P. S. Allen. 1996. A hydrothermal time model of seed after-ripening in Bromus tectorum L. Seed Sci. Res. 6:155-163.

Dahal, P. and K. J. Bradford. 1994. Hydrothermal time analysis of tomato seed germination at suboptimal temperature and reduced water potential. Seed Sci. Res. 4:71-80.

Debaene-Gill, S. B., P. S. Allen, and D. B. White. 1994. Dehydration of germinating perennial ryegrass seeds can alter rate of subsequent radicle emergence. J. Exp. Bot. 45:1301-1307.

de Miguel, L., M. J. Burgin, J. J. Casal, and R. A. Sánchez. 2000. Antagonistic action of low-fluence and high-irradiance modes of response of phytochrome on germination and beta-mannanase activity in Datura ferox seeds. J. Exp. Bot. 51:1127-1133.

Dorado, J., E. Sousa, I. M. Calha, J. L. González-Andújar, and C. FernándezQuintanilla. 2009. Predicting weed emergence in maize crops under two contrasting climatic conditions. Weed Res. In press.

Finch-Savage, W. E., J.R.A. Steckel, and K. Phelps. 1998. Germination and postgermination growth to carrot seedling emergence: predictive threshold models and sources of variation between sowing occasions. New Phytol. 139:505-516.

Grundy, A. C. 2003. Predicting weed emergence: a review of approaches and future challenges. Weed Res. 43:1-11.

Grundy, A. C., K. Phelps, R. J. Reader, and S. Burston. 2000. Modelling the germination of Stellaria media using the concept of hydrothermal time. New Phytol. 148:433-444.

Gummerson, R. J. 1986. The effect of constant temperatures and osmotic potential on the germination of sugar beet. J. Exp. Bot. 37:729-741.

Hardegree, S. P. and W. E. Emmerich. 1990. Effect of polyethylene glycol exclusion on the water potential of solution-saturated filter paper. Plant Physiol. 92:462-466.

Kebreab, E. and A. J. Murdoch. 1999. Modelling the effects of water stress and temperature on germination rate of Orobanche aegyptiaca seeds. J. Exp. Bot. 50:655-664.

Meyer, S. E., S. B. Debaene-Gill, and P. S. Allen. 2000. Using hydrothermal time concepts to model seed germination response to temperature, dormancy loss, and priming effects in Elymus elymoides. Seed Sci. Res. 10:213-223.

Ni, B. R. and K. J. Bradford. 1993. Germination and dormancy of abscisic acidand gibberellin-deficient mutant tomato seeds. Sensitivity of germination to abscisic acid, gibberellin, and water potential. Plant Physiol. 101:607617.

Roman, E. S., A. G. Thomas, S. D. Murphy, and C. J. Swanton. 1999. Modeling germination and seedling elongation of common lambsquarters (Chenopodium album). Weed Sci. 47:149-155.

Rowse, H. R. and W. E. Finch-Savage. 2003. Hydrothermal threshold models can describe the germination response of carrot (Daucus carota) and onion (Allium cepa) seed populations across both sub- and supra-optimal temperatures. New Phytol. 158:101-108.

Rowse, H. R., J.M.T. Mckee, and E. C. Higgs. 1999. A model of the effects of water stress on seed advancement and germination. New Phytol. 143:273-279.

Sánchez, R. A. and L. de Miguel. 1997. Phytochrome promotion of mannandegrading enzyme activities in the micropylar endosperm of Datura ferox seeds 
requires the presence of the embryo and gibberellin synthesis. Seed Sci. Res. 7:27-33.

Sánchez, R. A., L. de Miguel, C. Lima, and R. M. de Lederkremer. 2002. Effect of low water potential on phytochrome-induced germination, endosperm softening and cell-wall mannan degradation in Datura ferox seeds. Seed Sci. Res. 12:155-163.

Sánchez, R. A., L. de Miguel, and O. Mercuri. 1986. Phytochrome control of cellulase activity in Datura ferox $\mathrm{L}$. seeds and its relationship with germination. J. Exp. Bot. 37:1574-1580.
Shrestha, A., E. S. Roman, A. G. Thomas, and C. J. Swanton. 1999. Modeling germination and shoot-radicle elongation of Ambrosia artemisiifolia. Weed Sci. 47:557-562.

Winter, D. M. 1960. The development of the seed of Abutilon theophrasti. II. Seed coat. Am. J. Bot. 47:157-162.

Zanin, G. and M. Sattin. 1988. Threshold level and seed production of velvetleaf (Abutilon theophrasti Medicus) in maize. Weed Res. 28:347-352.

Received July 31, 2008, and approved October 24, 2008. 